\title{
LAND USE COMPATIBILITY ASSESSMENT USING A MDIFIED TOPSIS MODEL: A CASE STUDY OF ELEMENTARY SCHOOLS IN TEHRAN
}

\author{
A. Abedini ${ }^{\text {a }}$, M. Lotfian ${ }^{\text {b }}$, M. Moradi ${ }^{\text {a* }}$ \\ ${ }^{\text {a }}$ School of Surveying and Geospatial Engineering, University of Tehran, Tehran, Iran - (aabedeni, milad.moradi)@ut.ac.ir \\ ${ }^{\mathrm{b}}$ School of Civil and Environmental and Geomatics Engineering, Politecnico di Milano, polo di Como, Como, Italy - \\ maryam.lotfian@mail.polimi.it
}

KEY WORDS: GIS, Urban Planning, TOPSIS, OWA, Land use Compatibility, Tehran

\begin{abstract}
:
Being one of the most controversial issues in urban planning, land use planning has always been in the focus of researches. Land use planning is a subdivision of urban planning which tends to arrange land uses in order to avoid conflicts among them. In order to achieve a transparent and effective urban planning, land uses should be located and allocated in an ideal situation so that avoid negative impacts from neighbouring parcels and land uses. Neighbouring land uses can produce externalities and negative impacts on other land uses because of inter-land use interaction. These externalities may be undesirable effects such as noise, air and visual pollution or may be caused by hazardous facilities. The main objective of this research is to propose a new multi-criteria evaluation model for land use compatibility assessment. Considering the fact that a considerable number of factors affect the compatibility degree of neighbouring land uses, a multi-criteria evaluation approach is employed to address the aforementioned problem. This research employs the integration of Technique for Order of Preference by Similarity to Ideal Solution (TOPSIS) and Ordered Weighted Averaging (OWA) methods to facilitate land use compatibility evaluation with respect to optimism degree. The applicability of the proposed model is illustrated by the problem of land use compatibility assessment for elementary schools in Tehran. The results indicate that most of the current schools are situated in a location which is incompatible for the land use type of elementary school especially in the southern and central parts of the city.
\end{abstract}

\section{INTRODUCTION}

Land use planning is a field of science which tends to order and regulate different land uses in urban areas in an efficient situation (Adhikari \& Li, 2013; Musakwa \& van Niekerk, 2014; Stewart \& Janssen, 2014). Therefore, the aim of this discipline is to prevent conflict between land uses (Hashem \& Balakrishnan, 2014). In other words, the best land uses are assigned to each part of the land to have minimum incompatibility and externality between land uses (Taleai, Sharifi, Sliuzas, \& Mesgari, 2007). Land use planning is a crucial problem in cities which are rapidly growing because lack of an efficient plan contributes to urban sprawl and can cause huge problems in future (Mosadeghi, Warnken, Tomlinson, \& Mirfenderesk, 2015). In order to determine whether two adjacent land uses are incompatible or not, in the first step, needs and characteristics of each land use should be analysed. Considering the fact that most parcels have an external effect on neighbouring land uses, a well-structured study is required to assess the effect of parcels in a neighbourhood on each other. In addition, due to the fact that many factors contribute in the degree of compatibility of urban land uses, the problem of land use compatibility analyses is a multi criteria evaluation problem (Sheikhian, Pahlavani, \& Sabzevari; Taleai et al., 2007). Thus, multi criteria evaluation model can be employed to assess the degree of incompatibility between each parcel with its neighbours.

In this paper a MCDM model based on the integration of TOPSIS and OWA is employed to analyse the land use compatibility of elementary schools in Tehran (Pazand \& Hezarkhani, 2015). Due to the fact that children are vulnerable, the location of an elementary school should be selected based on many contributing factors. For example, children should be away from hazardous facilities such as gas stations. Moreover, elementary schools should not be near the noisy facilities which can disturb the children. In order to have a reliable framework for land use compatibility analysis of elementary schools, a MCDM model is proposed in this paper using TOPSIS model. TOPSIS is a multi-criteria evaluation model which is able to find the most similar alternative to the ideal solution and the least similar alternative to the negative ideal solution (Chen, 2000). Moreover, OWA facilitates decision making with respect to the optimism degree of the experts. Hence, the integration of the two models enables the decision maker to analyse the alternatives based on not only its similarity to the ideal solution but also the decision maker's optimism degree (Milad Moradi, Delavar, \& Moshiri, 2015).

Extensive research have been undertaken to propose a reliable framework based on MCDM algorithms for land use planning (Matthews, Sibbald, \& Craw, 1999; Mosadeghi et al., 2015; Storie, 2013; Su-xia \& He-bing, 2010; Zhang, Li, \& Fung, 2012). Zhang et al. (2012) used GIS-based multi criteria decision making for conflict resolution in land use planning. They assessed both attribute values and spatial extent of spatial objects. Mosadeghi et al. (2015) employed a GIS-based MCDM model using analytical hierarchy process for land use planning problem. They employed a fuzzy model to handle fuzzy uncertainties associated with input data and current land use layers. In another research Taleai et al. (2007) implemented a spatial decision support system for land use compatibility assessment in Tehran. The model was able to take a range of criteria into account including hazardous facilities, road

\footnotetext{
* Corresponding author
} 
networks, industrial units and educational facilities. A further superiority of this model is its ability to work with 3 dimensional data because sometimes incompatibility occurs between different floors of a building. Masoomi, Mesgari, and Hamrah (2013) used particle swarm optimisation for optimum allocation of urban land uses. They proposed a model that can find an optimum arrangement of a set of urban land uses in a neighbourhood. The main objective of the study of Masoomi et al. (2013) is to arrange land uses properly so that they do not interfere with one another. Sheikhian et al. used artificial neural network for analysing land use incompatibilities in a macro scale. They employed artificial neural network and asset of sample data to train the system for classification of different land parcels in five classes including highly compatible, compatible, moderately compatible, least compatible and incompatible. One superiority of their model is the use of real data for training the system instead of the use of expert's knowledge.

\section{METHODOLOGY}

\subsection{Ordered Weighted Averaging}

The OWA operator is an aggregating operator that has been widely used in multi criteria decision making (Milad Moradi et al., 2015). Generally speaking, OWA is an extension of two fundamental classes of operator including And and Or (Ouma, Kipkorir, \& Tateishi, 2011). These two operators are called Boolean operators and have been used traditionally in MCDM. Considering the fact that And and Or are two extreme cases which can satisfy all and at least one of criteria, OWA provides a range of answers from And to Or operator (Malczewski \& Liu, 2014). OWA calculates an aggregated value for each alternative using the following aggregation function (Yager, 1988):

$$
\begin{gathered}
F\left(a_{1}, \ldots, a_{n}\right)=\sum_{i=1}^{n} w_{i} * b_{i}= \\
w_{1} b_{1}+w_{2} b_{2}+\ldots+w_{n} b_{n}
\end{gathered}
$$

where $\quad w_{i}=$ the weight associated to $i$ th criteria

$$
b_{i}=\text { the } i \text { th attribute value }
$$

One of the critical steps in decision making with OWA is determining the weights for each criterion. There are several methods for obtaining OWA weights including linguistic quantifiers and expert's knowledge (Ouma et al., 2011). Linguistic quantifiers are natural language expressions that can convert expressions from natural languages to mathematical formulas (Milad Moradi et al., 2015). These quantifiers help experts input their opinion into decision making models (M Moradi, Delavar, Moshiri, \& Khamespanah, 2014). The level of optimism can be determined using a linguistic quantifier. Let $Q$ be a linguistic quantifier, the corresponding weight vector could be calculated as (Filev \& Yager, 1998):

$$
\begin{gathered}
W_{i}=Q_{R I M}\left(\frac{i}{n}\right)-Q_{R I M}\left(\frac{i-1}{n}\right) \\
i=1,2, \ldots, n
\end{gathered}
$$

where

$w_{i}=$ the weight of $i$ th criterion $Q=$ the linguistic quantifier
The quantifier can be expressions such as All, Most, Half, Few and At least one. All means all of the criteria should be satisfied, while half means the satisfaction of only half of the criteria is enough for an acceptable result. In addition, at least one indicates that an alternative that have a high score in only one of the criteria is good enough for being a candidate answer (M Moradi, Delavar, \& Moshiri, 2013). Therefore, the OWA operator can be calculated as:

$$
\begin{aligned}
& O W A_{i}=\sum_{j=1}^{n}\left(\left(\sum_{k=1}^{j} u_{k}\right)^{\alpha}-\left(\sum_{k=1}^{j-1} u_{k}\right)^{\alpha}\right) z_{i j} \\
& \text { where } \quad i=1,2, \ldots, n \\
& z_{i 1}>z_{i 2}>\ldots>z_{i n} \\
& u_{k}=\text { attribute value of } \mathrm{k}_{\mathrm{th}} \text { criterion }
\end{aligned}
$$

\subsection{TOPSIS Method}

TOPSIS is a method which enables decision makers to rank the alternatives based on their similarity to the ideal solution (Boran, Genç, Kurt, \& Akay, 2009). Four steps should be done to solve a MCDM problem including establishing a decision tree for ranking, computing the normalized score matrix, calculate the weighted normal matrix and determining the positive and negative ideal solutions. The decision matrix would be as follows (Chen, 2000):

$$
\begin{aligned}
& \begin{array}{lllllll}
F_{1} & F_{2} & \ldots & F_{j} & \ldots & F_{n}
\end{array} \\
& D=\begin{array}{c}
A_{1} \\
A_{2} \\
\cdot \\
\cdot \\
A_{3} \\
\cdot \\
\cdot \\
A_{J}
\end{array}\left[\begin{array}{llllll}
f_{11} & f_{12} & \ldots & f_{1 j} & \ldots & f_{1 n} \\
f_{21} & f_{22} & \ldots & f_{2 j} & \ldots & f_{2 n} \\
\cdot & \cdot & \ldots \ldots & \cdot & \ldots \ldots & \cdot \\
. & . & \ldots \ldots & . & \ldots \ldots & \cdot \\
f_{i 1} & f_{i 2} & \ldots & f_{i j} & \ldots & f_{i n} \\
\cdot & . & \ldots & . & \ldots & \cdot \\
\cdot & . & \ldots & . & \ldots & \cdot \\
f_{J 1} & f_{J 2} & \ldots & f_{J j} & \ldots & f_{J n}
\end{array}\right]
\end{aligned}
$$

where $\quad A_{i}=$ the $i$ th alternative $F_{j}=j$ th criterion

$F_{i j}$ represents the performance of $i$ th alternative in the $j$ th criterion.

The next step is to calculate normalized decision matrix which is a key for finding the optimum alternative. Because of the fact that different criteria represent different quantities, they are not necessarily comparable. Therefore, TOPSIS method calculates normalized decision matrix. The normalized decision matrix can be computed as (Chen, 2000):

$$
\begin{gathered}
r_{i j}=\frac{f_{i j}}{\sqrt{\sum_{j=1}^{n} f^{2}}} \\
j=1,2, \ldots, n \quad i=1,2, . ., n
\end{gathered}
$$

where 
The next step is to calculate the weighted normalized matrix because all the criteria do not have the same level of importance. The weighted normalized decision matrix is calculated as:

$$
V_{i j}=w_{i} * r_{i j} \quad i=1,2, \ldots, \mathrm{n} \quad j=1,2, \ldots, \mathrm{n}
$$

where $V_{i j}$ is weighted normalized decision matrix.

Then, all criteria should be classified into two main categories including positive and negative. The first set denotes the criteria that higher scores of alternatives are desired, whereas lower attribute values are preferable in negative criteria (Alabi, Sonder, Oduwole, \& Okafor, 2012; Debnath, 2013).

\subsection{Integration of OWA and TOPSIS}

In traditional multi-criteria evaluation models the weights are included into the model using a weighted linear combination and it is not possible to have surveillance on the Orness of the combination. In the proposed model, the third step is calculated as:

$$
\begin{gathered}
V_{i j}=O W A_{\text {Ormess }_{i}}\left(w_{i}, r_{i j}\right) \\
i=1,2, \ldots, \mathrm{n} \quad j=1,2, \ldots, \mathrm{n}
\end{gathered}
$$

The OWA operator here is able to take the optimism degree (or Orness) into account, whereas the weighted linear combination is only able to combine the attribute values based on simple weights which indicate their relative significance. In other words, in the proposed model, the overall score of every alternative is computed using an OWA operator which uses TOPSIS scores as input values. One advantage of this model is its power in combining different attribute values regarding the optimism degree.

\section{IMPLEMENTATION}

\subsection{Study Area}

The study area of this research is Tehran metropolitan area which is located in the central part of Iran. In recent years, due to rapid urban growth, many land uses are assigned badly which caused significant incompatibility and externality among adjacent land parcels. Elementary schools which are noticeably important in educating the next generation in a confortable environment. Currently, many schools in Tehran are constructed near highways or hazardous facilities which caused negative impacts on the quality of educational system. In this paper the situation of these schools is analysed through a multi-criteria evaluation model.

\subsection{Contributing Criteria}

The land use compatibility analysis problem is a MCDM problem and depends on a number of factors. Figure 1 depicts the contributing factors that have been employed in previous researches. A number of different data layers are used in previous researches which represent three main groups of criteria which are related to noise pollution, air pollution and safety. However, due to limited access to up to date data, in this research only eight criteria are included. Table 1 indicates the data layers used in this paper. Distance to roads and high ways is a very important criterion representing noise pollution. In additions, elementary schools should be constructed far from military bases and air ports where there are too much air and noise pollution. Considering the fact that hospitals are source of

\begin{tabular}{|c|c|c|c|}
\hline ID & Contributing factors & Name & References \\
\hline 1 & Distance to Roads & D_HW & $\begin{array}{ll}(\text { Tarhan } & \& \\
\text { Deniz, 2013) } & \end{array}$ \\
\hline 2 & Distance to Airports & D_AP & $\begin{array}{l}\text { (Mandal, 2014; } \\
\text { Storie, 2013) }\end{array}$ \\
\hline 3 & $\begin{array}{l}\text { Distance to Hazardous } \\
\text { Facil. }\end{array}$ & D_HF & $\begin{array}{l}\text { (Milad Moradi et } \\
\text { al., 2015) }\end{array}$ \\
\hline 4 & Distance to Stadiums & D_St & $\begin{array}{l}\text { Mandal, 2014; } \\
\text { Masoomi et al., } \\
\text { 2013) }\end{array}$ \\
\hline 5 & $\begin{array}{l}\text { Distance to Gas } \\
\text { Stations }\end{array}$ & D_GS & $\begin{array}{l}\text { Mosadeghi et } \\
\text { al., 2015; Storie, } \\
\text { 2013) }\end{array}$ \\
\hline 6 & $\begin{array}{l}\text { Distance to Military } \\
\text { Bases }\end{array}$ & D_MB & (Storie, 2013) \\
\hline 7 & Distance to Faults & D_Fl & $\begin{array}{l}\text { (Stewart \& } \\
\text { Janssen, 2014) }\end{array}$ \\
\hline 8 & Distance to Hospitals & D_Hp & $\begin{array}{l}\text { (Sheikhian et al.; } \\
\text { Zhang et al., } \\
\text { 2012) }\end{array}$ \\
\hline
\end{tabular}
contagious diseases, land parcels near to hospitals are incompatible with elementary schools.

Table 1. Contributing factors

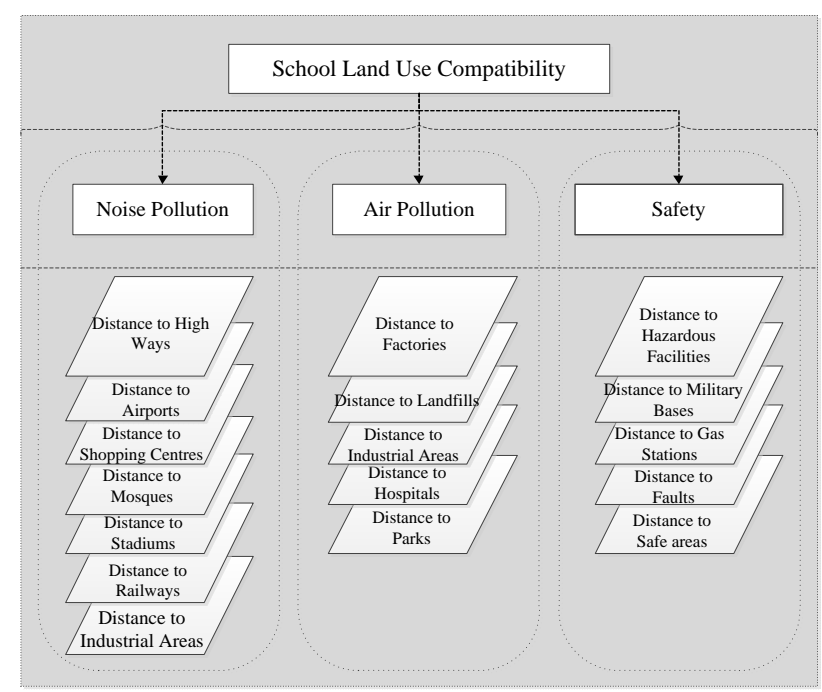

Figure 1. Data layer used in previous models

\subsection{Model Implementation}

The model is implemented based on the steps that are shown in Figure 2. Firstly, contributing criteria which affect the land use compatibility of urban areas for elementary schools are determined. Then, the input map layers are produced (as shown in Figure 3). Input map layer are then normalised to be comparable with each other. In the normalisation procedure, the attribute values of all criteria are mapped to a range between 0 and 1. Following that, expert's knowledge is obtained using a number of data tables. After that, these information tables are employed to produce decision matrix using TOPSIS method. In the next step, the decision matrix is normalised and normalised decision matrix is generated. In the next step, based on the proposed method, the normalised decision matrix is used in OWA model to produce weighted normalised decision matrix. 
In this step, OWA is used instead of TOPSIS method to provide a range of answers from And to Or (traditional aggregation operators). Then, two types of criteria should be determined, ideal criteria and negative ideal criteria. Criteria that high attribute values of them are preferable, are applied for ideal solution, while the criteria that lower attribute values are desirable, are used for computing negative ideal solution. Finally Equation (6) is used to calculate a degree of incompatibility between elementary schools and their neighbouring land parcels and incompatibility maps are produced using ArcGIS software (see Figure 4).

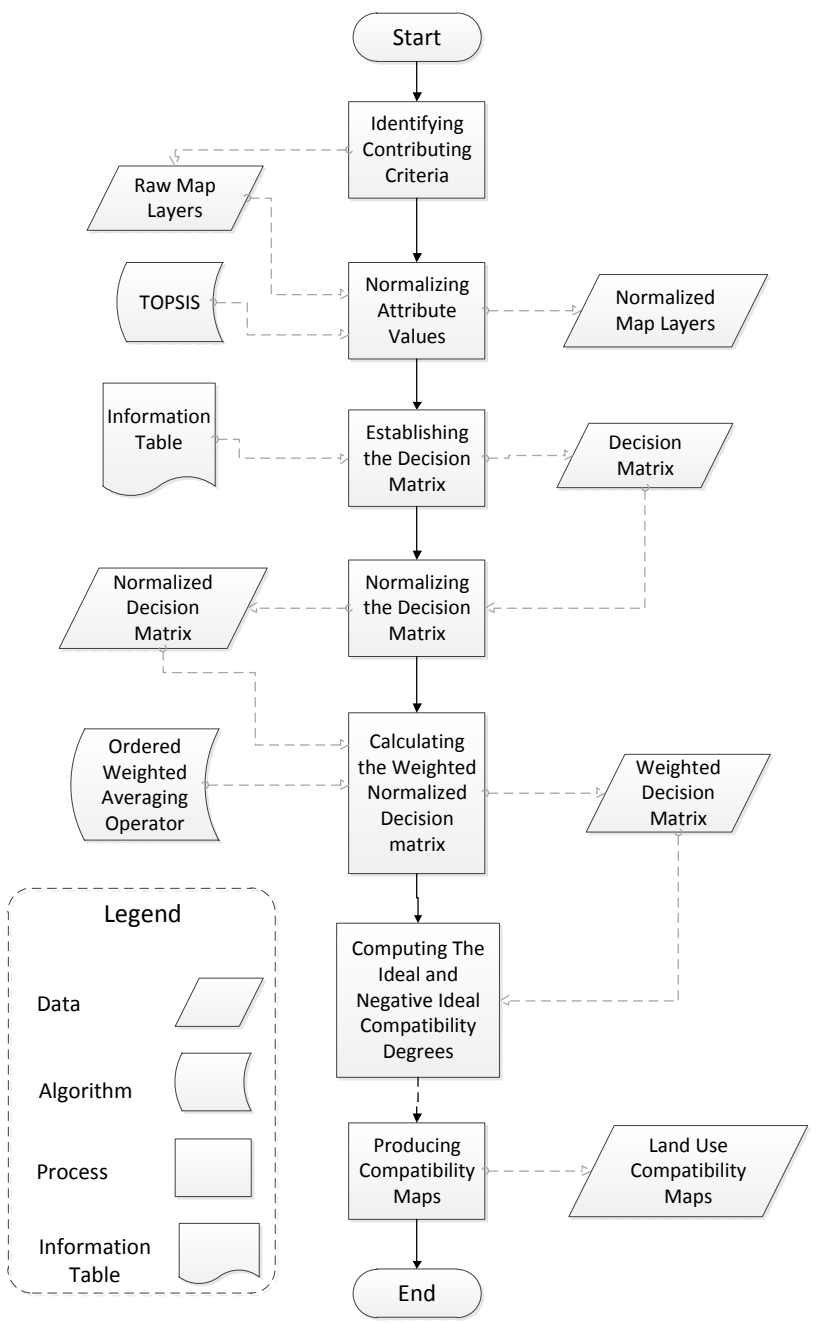

Figure 2. Steps of the proposed land use compatibility model

Figure 2 depicts all the steps done in this paper to produce compatibility maps, all the data sets and data layers that inserted into the model or produced in different parts of the model and all algorithms that are employed to produce land use compatibility maps for elementary schools.

Figure 3 illustrates different map layers used in this paper. These layers include distance to air ports, distance to faults, distance to gas stations, distance to hazardous facilities, distance to roads, distance to stadiums, distance to hospitals and distance to military bases. Firstly, a map is produced based on the distance of each parcel to the abovementioned facility. Then, in order to make different map layers comparable, all layers are normalised between 0 and 1. As shown in Figure 3, there are three main faults in Tehran metropolitan area including Mosha fault, North Tehran fault and ray fault. Therefore, central part of
Tehran is far from faults and is safe for elementary schools. In addition, there are three air ports in central and southern part of Tehran that can be dangerous for children.

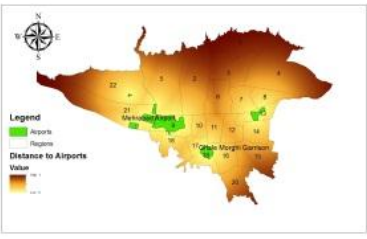

Distance to Airport

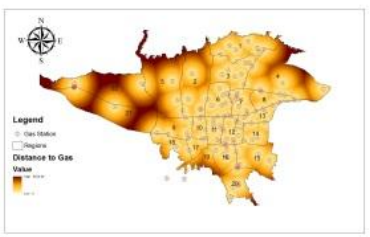

Distance to Gas Station

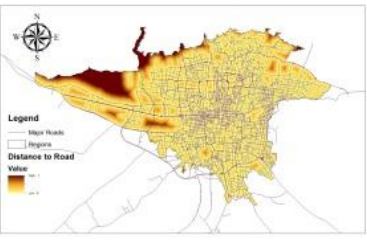

Distance to Roads

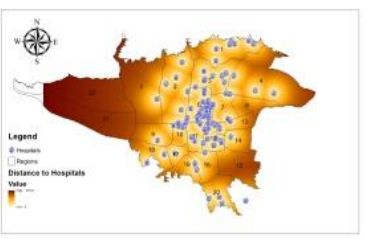

Distance to Hospitals

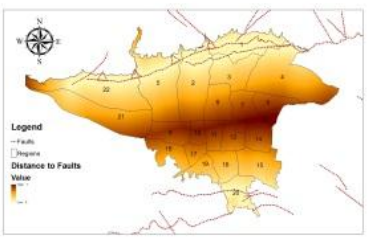

Distance to Faults

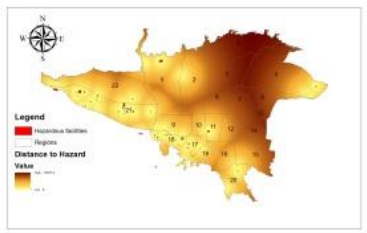

Distance to Hazarddous

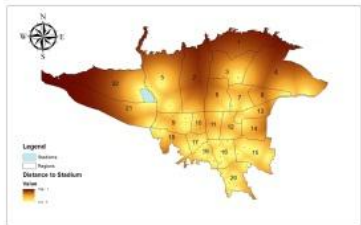

Distance to Stadiums

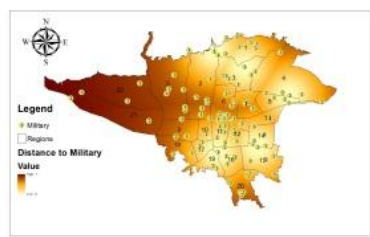

Distance to Mllitary
Figure 3. Input map layers used in this paper

\subsection{Results and Discussion}

The results of this paper indicate the degree to which each parcel is compatible with the land use of elementary schools. The resulted map shows that which places are suitable for building a new schools based on the adjacent parcels. In addition, the compatibility map can determine the elementary schools which are not located in a suitable location. In other words, this research specifies the schools that their land use is not compatible with their neighbours. Therefore, this research can play a significant role in urban planning by providing information on how suitable are different locations for construction of an elementary school. The model is implemented using the steps shown in Figure 2 and a land use compatibility degree is calculated for each parcel. Then, these compatibility degrees are normalised from 0 to 1 and are employed to produce a land use compatibility map for elementary schools in Tehran. Figure 4 illustrates the degree of compatibility for different areas of Tehran. 


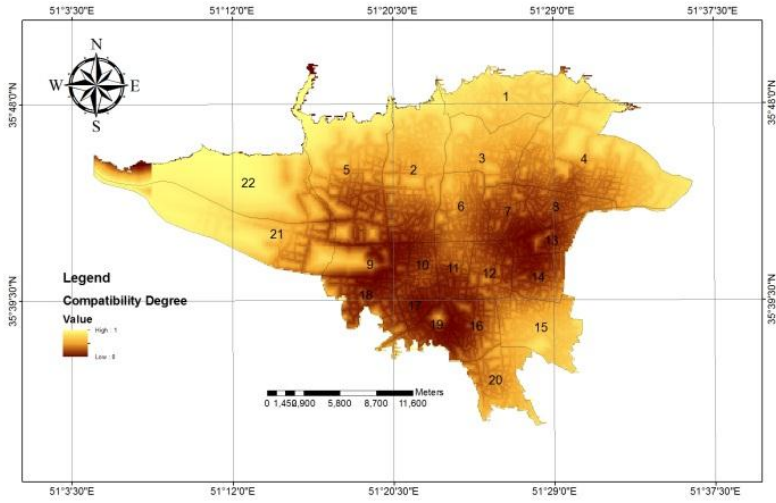

Figure 4. Land use compatibility map for elementary schools

\section{CONCLUSION}

This paper proposes a new multi-criteria decision making model for land use compatibility analysis. This model is able to evaluate the degree of compatibility of each neighbourhood with the land use of elementary schools. There are different criteria that affect the compatibility degree of each parcel for being an elementary school but due to the limited accessibility to current data, only eight criteria are used in the paper. TOPSIS method which is able to compute the overall score based on the similarity to the ideal and negative ideal solutions, is employed in this research. Moreover, OWA is applied in order to facilitate the analysis of decision maker's optimism degree. The results indicate that most parcels in the central parts and southern parts of Tehran are incompatible with building an elementary school. Furthermore, most of the schools in the southern part of Tehran are located in a place which is incompatible with their land use. This MCDM model can be used in other areas with minor modifications.

\section{REFERENCES}

Adhikari, B., \& Li, J. (2013). Modelling ambiguity in urban planning. Annals of GIS, 19(3), 143-152.

Alabi, T., Sonder, K., Oduwole, O., \& Okafor, C. (2012). A multi-criteria GIS site selection for sustainable cocoa development in West Africa: A case study of Nigeria. International Journal of Applied Geospatial Research (IJAGR), 3(1), 73-87.

Boran, F. E., Genç, S., Kurt, M., \& Akay, D. (2009). A multicriteria intuitionistic fuzzy group decision making for supplier selection with TOPSIS method. Expert Systems with Applications, 36(8), 11363-11368.

Chen, C.-T. (2000). Extensions of the TOPSIS for group decision-making under fuzzy environment. Fuzzy sets and systems, 114(1), 1-9.

Debnath, R. (2013). An assessment of spatio-temporal pattern of urban earthquake vulnerability using GIS: a study on Dhaka City. Annals of GIS, 19(2), 63-78.

Filev, D., \& Yager, R. R. (1998). On the issue of obtaining OWA operator weights. Fuzzy sets and systems, 94(2), 157-169.
Hashem, N., \& Balakrishnan, P. (2014). Change analysis of land use/land cover and modelling urban growth in Greater Doha, Qatar. Annals of GIS(ahead-of-print), 1-15.

Malczewski, J., \& Liu, X. (2014). Local ordered weighted averaging in GIS-based multicriteria analysis. Annals of GIS, 20(2), 117-129.

Mandal, U. K. (2014). Geo-information Based Spatio-temporal Modeling of Urban Land Use and Land Cover Change in Butwal Municipality, Nepal. ISPRS-International Archives of the Photogrammetry, Remote Sensing and Spatial Information Sciences, 1, 809-815.

Masoomi, Z., Mesgari, M. S., \& Hamrah, M. (2013). Allocation of urban land uses by Multi-Objective Particle Swarm Optimization algorithm. International Journal of Geographical Information Science, 27(3), 542-566.

Matthews, K. B., Sibbald, A. R., \& Craw, S. (1999). Implementation of a spatial decision support system for rural land use planning: integrating geographic information system and environmental models with search and optimisation algorithms. Computers and electronics in agriculture, 23(1), 926.

Moradi, M., Delavar, M., \& Moshiri, B. (2013). Sensitivity analysis of ordered weighted averaging operator in earthquake vulnerability assessment. ISPRS-International Archives of the Photogrammetry, Remote Sensing and Spatial Information Sciences, 1(3), 277-282.

Moradi, M., Delavar, M., Moshiri, B., \& Khamespanah, F. (2014). A Novel Approach to Support Majority Voting in Spatial Group MCDM using Density Induced OWA Operator for Seismic Vulnerability Assessment. ISPRS-International Archives of the Photogrammetry, Remote Sensing and Spatial Information Sciences, 1, 209-214.

Moradi, M., Delavar, M. R., \& Moshiri, B. (2015). A GISbased multi-criteria decision-making approach for seismic vulnerability assessment using quantifier-guided OWA operator: a case study of Tehran, Iran. Annals of GIS, 21(3), 209-222.

Mosadeghi, R., Warnken, J., Tomlinson, R., \& Mirfenderesk, H. (2015). Comparison of Fuzzy-AHP and AHP in a spatial multi-criteria decision making model for urban land-use planning. Computers, Environment and Urban Systems, 49, 5465.

Musakwa, W., \& van Niekerk, A. (2014). Monitoring Urban Sprawl and Sustainable Urban Development Using the Moran Index: A Case Study of Stellenbosch, South Africa. International Journal of Applied Geospatial Research (IJAGR), 5(3), 1-20.

Ouma, Y. O., Kipkorir, E. C., \& Tateishi, R. (2011). MCDAGIS integrated approach for optimized landfill site selection for growing urban regions: an application of neighborhoodproximity analysis. Annals of GIS, 17(1), 43-62.

Pazand, K., \& Hezarkhani, A. (2015). Porphyry $\mathrm{Cu}$ potential area selection using the combine AHP-TOPSIS methods: a case study in Siahrud area (NW, Iran). Earth Science Informatics, 8(1), 207-220. 
Sheikhian, H., Pahlavani, P., \& Sabzevari, A. Urban Land Use Compatibilities Evaluation Using An Artificial Neural Network Approximator In Micro-Scale.

Stewart, T. J., \& Janssen, R. (2014). A multiobjective GISbased land use planning algorithm. Computers, Environment and Urban Systems, 46, 25-34.

Storie, C. D. (2013). Intra-Urban Analysis of Commercial Locations A GIS-Based Approach. International Journal of Applied Geospatial Research (IJAGR), 4(1), 1-16.

Su-xia, Z., \& He-bing, Z. (2010). Research and Design of Land-Use Planning Implementary Evaluation Aid DecisionMaking System Based on GIS. Paper presented at the Information Technology and Applications (IFITA), 2010 International Forum on.

Taleai, M., Sharifi, A., Sliuzas, R., \& Mesgari, M. (2007). Evaluating the compatibility of multi-functional and intensive urban land uses. International Journal of Applied Earth Observation and Geoinformation, 9(4), 375-391.

Tarhan, C., \& Deniz, D. (2013). Sustainable Urban Planning and Risk Assessment of Earthquake Hazards in Turkey. ISPRSInternational Archives of the Photogrammetry, Remote Sensing and Spatial Information Sciences, 1(1), 113-117.

Yager, R. R. (1988). On ordered weighted averaging aggregation operators in multicriteria decisionmaking. Systems, Man and Cybernetics, IEEE Transactions on, 18(1), 183-190.

Zhang, Y., Li, A., \& Fung, T. (2012). Using GIS and multicriteria decision analysis for conflict resolution in land use planning. Procedia Environmental Sciences, 13, 2264-2273. 